\title{
Characterisation of sixteen additional polymorphic microsatellite loci for the spreading but locally rare European butterfly, Brenthis ino (Lepidoptera: Nymphalidae)
}

\author{
Christophe LEBIGRE, Camille TURLURE and Nicolas SCHTICKZELLE
}

Earth and Life Institute, Biodiversity Research Centre, Université catholique de Louvain, Croix du Sud 4, L7.07.04, B-1348 Louvainla-Neuve, Belgium; e-mails: christophe.lebigre@uclouvain.be; camille.turlure@uclouvain.be; nicolas.schtickzelle@uclouvain.be

Key words. Lepidoptera, Nymphalidae, Brenthis ino, lesser marbled fritillary, connectivity, inbreeding, landscape genetics, microsatellite, null alleles

\begin{abstract}
Whilst the overall geographic range of the lesser marbled fritillary, Brenthis ino (Rottemburg, 1775), is currently expanding, this species is patchily distributed at a local spatial scale due to its use of flower rich semi-natural meadows and the aggregated distribution of its host plant. Therefore, understanding the dispersal patterns of this butterfly and the effect of increasing fragmentation of the landscapes in central and Western Europe on its population dynamics is key to determining whether this patchy distribution can lead to metapopulation structuring and dynamics. One way to determine the degree to which local populations are isolated from one another is to use high resolution molecular genetic markers and thence quantify gene flow and genetic drift. Eleven microsatellite loci have previously been developed for this species, but six showed evidence of null alleles, effectively violating key assumptions of the models used to infer gene flow. We therefore developed a set of new primer pairs to amplify a suite of 16 highly polymorphic microsatellite loci (number of alleles ranged from 2-30) of which nine were found to conform to the Hardy-Weinberg's expectations, whilst at the same time not showing any clear signature for the presence of null alleles. We further describe how these primers were optimized for landscape and metapopulation genetics studies in Belgian Ardenne.
\end{abstract}

\section{INTODUCTION}

The lesser marbled fritillary, Brenthis ino (Rottemburg, 1775) (Lepidoptera: Nymphalidae), mainly inhabits humid grasslands, and wet areas such as bogs and marshes. Its large geographical distribution ranges from Northern Japan to Western Europe, with populations assessed as either stable (Parmesan et al., 1999) or slightly expanding southward in Europe (Parmesan et al., 1999; Van Swaay \& Warren, 1999; Zimmermann et al., 2005). This expansion and the associated increase in population sizes have primarily been associated with the expanding range of the meadowsweet (Filipendula ulmaria; family Rosaceae), the main larval host plant of this butterfly species which often grows during the eutrophication of wet meadows (Zimmerman et al., 2005). The local dynamics of $B$. ino is therefore in stark contrast with the decline observed in many other butterfly species inhabiting (semi-) natural wet meadows, such as the bog fritillary (Boloria eunomia Esper, 1799). Such contrasted population trends make $B$. ino invaluable for purposes of species comparison (see e.g. Zimmermann et al., 2005; Fric et al., 2010) and for further understanding the variation observed in the species' response to environmental changes and habitat degradation.

Determining whether the patchy distribution of this butterfly leads to the formation of metapopulation structuring (Hanski, 1999) requires quantifying the degree to which local populations are isolated and the frequency of movement among patches. While individuals' emigration propensity can be high and the dispersal distance of $B$. ino can be relatively large (exceeding $2 \mathrm{~km}$, Fric et al., 2010), another study showed that individuals may be very philopatric (Weyer \& Schmitt, 2013). These two previous studies were performed at very local scales in populations with very high densities, whereas to better understand the movements and gene flow of this butterfly species requires working at larger scales with populations of varying distribution and densities.
Microsatellites are highly polymorphic genetic markers that are widely used for the detection of genetic differentiations and diversities over a variety of spatio-temporal scales (e.g. Hall \& Beissinger, 2014). However, the development and availability of species-specific primers for polymorphic microsatellites is challenging in butterflies due to the widespread presence of null alleles and large allele dropout (Nève \& Meglécz, 2000; Meglécz et al., 2007; Sinama et al., 2011). This violates many assumptions of the models used to quantify spatial genetic structure and hence may lead to substantial biases in estimates of butterfly genetic characteristics. Eleven microsatellite markers have previously been described for B. ino (Molecular Ecology Resources Primer Development Consortium, 2012), but their suitability may be limited as two of the loci did not conform to Hardy-Weinberg expectations (HWe), whilst null alleles appeared likely in three others. As the six remaining markers had only a moderate number of alleles (range 4-9), we developed an additional set of microsatellite markers for $B$. ino to improve the statistical power of spatial genetic analyses and implement small scale landscape genetic studies.

\section{MATERIAL AND METHODS}

Genomic DNA was extracted from the legs of adults captured in five populations in the Belgian Ardenne. Each leg was kept in $90 \%$ ethanol in an individual Eppendorf tube and stored in $-20^{\circ} \mathrm{C}$ freezers prior to DNA extraction. DNA was extracted using a phenol-chloroform-isoamyl alcohol method as described in Vandewoestijne \& Baguette (2002). The last step of this method was modified such that dried genomic DNA was re-suspended in $20 \mu \mathrm{L}$, instead of $50 \mu \mathrm{L} 10 \mathrm{mM}$ Tris- $\mathrm{HCl} \mathrm{pH}$ 8.0, $1 \mathrm{mM}$ EDTA. The DNA extraction was subsequently treated by RNase $(2 \mu \mathrm{L}$ of $100 \mu \mathrm{g} / \mathrm{mL}$ RNase; incubation: $30 \mathrm{~min}$ at $37^{\circ} \mathrm{C}$ ). Microsatellites were isolated by GENOSCREEN (Lille, France) using the 
TABLE 1. Description of 16 polymorphic microsatellite loci developed for Brenthis ino. Abbreviations: Access. no. - the Genebank accession number; Range - allele size range; $\mathrm{Ta}$ - annealing temperature; Group - Multiplex group.

\begin{tabular}{|c|c|c|c|c|c|c|c|}
\hline Primer & Access. no. & Forward sequence & Reverse sequence & Colour & Range & & Sroup \\
\hline Bi_111 & KP164838 & CCGAAATCAGGCAGGATG & ACATGAGACTACTAACATAACCATGC & NED & $173-201$ & 55 & 1 \\
\hline Bi_112 & KP164839 & ATGTCACAGGATTAAAATAACTACGTG & GATATGCCAGGACCCTCCTT & 6-FAM & $196-283$ & 53 & 1 \\
\hline Bi_115 & KP164840 & GTTGAAGTACATTTATGTTCGTATGC & AACCATTTGCTCTTTGACAGC & NED & $192-250$ & 55 & 3 \\
\hline i_116 & KP164841 & TGTGTTGAAGCTTCTTGTTTAATAGG & GCTTGTGTTAATCCAGGGGT & PET & $115-205$ & 55 & 1 \\
\hline Bi_117 & KP164842 & AGTACCAAGGAGTTTGGCGA & CGTTACTGTGGCTGCGAGT & NED & $129-145$ & 53 & 1 \\
\hline Bi_119 & KP164843 & TCCTACGTGTCTGCTCCATTC & ATTGTAGGCTACCAACGCCA & NED & $151-187$ & 57 & 2 \\
\hline Bi_121 & KP164844 & TCATGATTGAGGACGGTGAA & CGTATACAAACGTATACTGTGACATCT & VIC & $127-156$ & 53 & 1 \\
\hline Bi_125 & KP164845 & AGGAGGATA & ACCGCGGAAAGGTATAAACG & VIC & $151-263$ & 53 & 3 \\
\hline Bi_126 & KP164846 & GTTCGAGCGATGGGTTGT & CACGTGACGCACCTAACATC & PET & $188-218$ & 57 & 2 \\
\hline Bi_128 & KP164847 & GTTTGTGTCACATGCGTGC & GGCGTGG & VIC & $291-361$ & 53 & 1 \\
\hline Bi_131 & KP164848 & GAGCTACGATGCCACAGACA & TTCGACTTAGCTTATCTCTGCAA & VIC & $152-186$ & 57 & 2 \\
\hline Bi_135 & KP164849 & CCCTAACAGAAAGGTCAAAATGA & CGTCACTCCGTTTTCGTCTT & PET & $131-169$ & 57 & 2 \\
\hline Bi_139 & KP164850 & TCGGGTGCGTCTCTAGGTAT & AAACAAATAATTTATGAGGATCGGA & VIC & $123-207$ & 57 & 2 \\
\hline Bi_141 & KP164851 & AGTGCTGCGATCCTCAGGT & TACCTAGGGACGAACCCGAT & PET & $145-147$ & 55 & 3 \\
\hline Bi_143 & KP164852 & TCTGGCGTT & AGTCCGTTGAGT & PET & $110-128$ & 57 & 3 \\
\hline Bi_144 & KP164853 & GTCCTGGGTTCAACTTCGGT & TCACTCTTCAAAATTTTACAGGACC & 6-FAM & $135-161$ & 57 & 2 \\
\hline
\end{tabular}

method described in Malausa et al. (2011). Briefly, a pool of the genomic DNA extracted from eight individuals was fragmented using the enzyme RsaI and subsequently enriched using eight probes with the repeat units TG, AAC, AGG, ACAT, TC, AAG, ACG, ACTC. The enriched DNA was amplified and sequenced using a GS-FLX ${ }^{\circledR}$ sequencer (Roche Diagnostics, Basel, Switzerland) to provide a total of 5,831 sequences containing microsatellite repeats. The software QDD (Meglécz et al., 2010) was used to analyze the sequences containing microsatellite repeats and to design primers. In total, 197 primer pairs were available of which 51 pairs were selected having a repeat number $>6$, and calculated annealing temperatures between $53-63^{\circ} \mathrm{C}$ (all pairs were di- or tetranucleotide repeats). The amplification of these 51 primer pairs was tested using polymerase chain reaction (PCR) in $10 \mu \mathrm{L}$ reaction volumes containing: $2 \mu \mathrm{L}$ of DNA, 0.7 units of DNA polymerase (Roche Diagnostics, Ref. 11435094 001), $0.3 \mathrm{mM}$ BSA, $10 \mathrm{mM}$ Tris-HCl, $\mathrm{pH} 8.0,50 \mathrm{mM}$ of $\mathrm{KCl}, 100 \mu \mathrm{M}$ dNTPs, $1 \mu \mathrm{M}$ primer, and $1.5 \mathrm{mM}$ of $\mathrm{MgCl}_{2}$ (these conditions were subsequently optimized and the range of primer and $\mathrm{MgCl}_{2}$ ranged from $0.5-1.3 \mu \mathrm{M}$ and $1.5-2.0 \mathrm{mM}$, respectively). Following a denaturation step at $95^{\circ} \mathrm{C}$ for $15 \mathrm{~min}$, DNA was amplified by 32 cycles of denaturation $\left(94^{\circ} \mathrm{C}\right.$ for $\left.30 \mathrm{~s}\right)$, incubation at the annealing temperature $(30 \mathrm{~s})$, followed by an extension step at $72^{\circ} \mathrm{C}(90 \mathrm{~s})$ and an additional elongation step $\left(74^{\circ} \mathrm{C}\right.$ for $\left.25 \mathrm{~min}\right)$. The amplified fragments were subsequently run on $1 \%$ agarose gels. Across the 51 pairs of primers selected, 31 were discarded as they yielded no PCR products (9 primers), produced a large number of bands indicating a lack of specificity (17 primers), or

TABLE 2. Characteristics of the 16 polymorphic microsatellite loci developed for Brenthis ino from five Belgian sampling sites. Descriptions are provided across all sites and within each site. Abbreviations: A - total number of alleles; Ho - observed heterozygosity; $H e$ - expected heterozygosity; $P_{G E N E P O P}$ - significance test for deviations of the Hardy-Weinberg's expectations (estimated across all sites using GENEPOP); $P_{\text {null }}$ - the frequency of null alleles (estimated using MICROCHECKER). For each study site, the number of genotypes (n) and the $P$-value of the deviation from the Hardy-Weinberg's expectations calculated using Arlequin $\left(P_{\text {Arlequin }}\right)$ are provided.

\begin{tabular}{|c|c|c|c|c|c|c|c|c|c|c|}
\hline \multirow[b]{2}{*}{ Primer } & \multicolumn{5}{|c|}{ Overall } & \multicolumn{5}{|c|}{ Within sites } \\
\hline & A & Ho & $\mathrm{He}$ & $P_{G E N E P O P}$ & $P_{\text {null }}$ & $\begin{array}{l}\text { Bérismenil } \\
\left(\mathrm{n} ; P_{\text {Arlequin }}\right)\end{array}$ & $\begin{array}{c}\text { Chapons } \\
\left(\mathrm{n} ; P_{\text {Arlequin }}\right)\end{array}$ & $\begin{array}{l}\text { Prés de la Lienne } \\
\quad\left(\mathrm{n} ; P_{\text {Arlequin }}\right)\end{array}$ & $\begin{array}{l}\text { Pont Hierlot } \\
\left(\mathrm{n} ; P_{\text {Arlequin }}\right)\end{array}$ & $\begin{array}{l}\text { Verleumont } \\
\left(\mathrm{n} ; P_{\text {Arlequin }}\right)\end{array}$ \\
\hline Bi_111 & 13 & 0.769 & 0.807 & 0.255 & -0.096 & $10 ; 1.00$ & $15 ; 0.01$ & $15 ; 0.92$ & $15 ; 0.73$ & $14 ; 0.10$ \\
\hline Bi_112 & 17 & 0.680 & 0.816 & 0.054 & -0.038 & $10 ; 0.37$ & $15 ; 0.01$ & $15 ; 0.43$ & $14 ; 0.21$ & $15 ; 0.09$ \\
\hline Bi_115 & 13 & 0.423 & 0.757 & $<0.001$ & 0.136 & $10 ; 0.06$ & $14 ;<0.01$ & $15 ; 0.23$ & $15 ; 0.05$ & $13 ;<0.01$ \\
\hline Bi_116 & 19 & 0.468 & 0.866 & $<0.001$ & 0.243 & $10 ;<0.01$ & $15 ; 0.05$ & $15 ; 0.03$ & $14 ; 0.02$ & $15 ;<0.01$ \\
\hline Bi_117 & 9 & 0.500 & 0.886 & $<0.001$ & 0.164 & $10 ; 0.04$ & $14 ; 0.10$ & $15 ;<0.01$ & $15 ;<0.01$ & $14 ;<0.01$ \\
\hline Bi_119 & 11 & 0.740 & 0.842 & 0.290 & 0.058 & $10 ; 0.45$ & $15 ; 0.45$ & $15 ; 0.25$ & $15 ; 0.05$ & $15 ; 0.45$ \\
\hline Bi_121 & 12 & 0.487 & 0.771 & $<0.001$ & 0.133 & $10 ; 0.10$ & $15 ; 0.02$ & $15 ;<0.01$ & $15 ; 0.03$ & $15 ;<0.01$ \\
\hline Bi_125 & 30 & 0.881 & 0.949 & 0.099 & -0.003 & $10 ; 0.72$ & $14 ; 0.30$ & $14 ; 0.30$ & $15 ; 0.09$ & $14 ;<0.01$ \\
\hline Bi_126 & 11 & 0.837 & 0.787 & 0.542 & -0.159 & $10 ; 0.62$ & $15 ; 0.31$ & $14 ; 0.85$ & $15 ; 0.49$ & $15 ; 0.14$ \\
\hline Bi_128 & 15 & 0.647 & 0.829 & 0.001 & 0.022 & $10 ; 0.35$ & $15 ; 0.05$ & $15 ; 0.63$ & $15 ; 0.01$ & $15 ;<0.01$ \\
\hline Bi_131 & 7 & 0.264 & 0.423 & 0.005 & 0.281 & $10 ;<0.01$ & $14 ; 0.49$ & $15 ; 0.07$ & $14 ; 1.00$ & $15 ; 0.31$ \\
\hline Bi_135 & 10 & 0.256 & 0.805 & $<0.001$ & 0.284 & $7 ;<0.01$ & $14 ;<0.01$ & $13 ;<0.01$ & $12 ;<0.01$ & $8 ;<0.01$ \\
\hline Bi_139 & 12 & 0.811 & 0.854 & 0.737 & 0.126 & $10 ; 0.19$ & $15 ; 0.97$ & $14 ; 0.98$ & $15 ; 0.82$ & $15 ; 0.34$ \\
\hline Bi_141 & 2 & 0.071 & 0.071 & - & - & 10 ; NA & $14 ; 1.00$ & $15 ; \mathrm{NA}$ & 15; NA & $15 ; \mathrm{NA}$ \\
\hline Bi_143 & 9 & 0.770 & 0.756 & 0.687 & -0.102 & $10 ; 1.00$ & $14 ; 0.88$ & $15 ; 0.93$ & $15 ; 0.34$ & $15 ; 0.07$ \\
\hline Bi_144 & 7 & 0.673 & 0.754 & 0.113 & -0.143 & $10 ; 0.45$ & $15 ; 0.08$ & $15 ; 0.85$ & $15 ; 0.02$ & $15 ; 0.16$ \\
\hline
\end{tabular}


yielded weak PCR products (5 primers). For the remaining 20 primers, forward primers were labelled using fluorescent dyes NED, 6-FAM, PET, and VIC from Applied Biosystems (Carlsbad, CA, USA; Table 1). Individuals were genotyped using a Prism ${ }^{\circledR} 3100$ Applied BioSystems genetic analyser, allele sizes being scored using GeneMapper 3.7® (Applied Biosystems). The size of the alleles was estimated by scoring their size against an internal standard (600-LIZ, Applied Biosystems). Multiplex amplifications were performed using QIAGEN Multiplex PCR Kit (Qiagen, Venlo, Netherlands) using the protocol: $95^{\circ} \mathrm{C}$ for $15 \mathrm{~min}$ followed by 25 cycles denaturation $\left(94^{\circ} \mathrm{C}\right.$ for $\left.30 \mathrm{~s}\right)$, incubation at the annealing temperatures $(90 \mathrm{~s})$, denaturation $\left(72^{\circ} \mathrm{C}\right.$ for $\left.90 \mathrm{~s}\right)$ and with a final denaturation $\left(72^{\circ} \mathrm{C}\right.$ for $\left.45 \mathrm{~min}\right)$. At this stage, four additional primers were discarded because of interactions with other primers when performing multiplex PCRs. The remaining 16 primers therefore had similar annealing temperatures and allowed multiplex amplifications of the target amplicons (Table 1).

Deviations from the HWe were estimated across all studied populations using GENEPOP 3.3 (Raymond \& Rousset, 1995) and within each population using ARLEQUIN v3.1 (Excoffier et al., 2007). We more specifically tested whether some loci were consistently lacking heterozygosity by calculating for each locus the proportion of populations in which significant deviations from the HWe were recorded ( $\alpha$ adjusted $=0.003$ ). We further quantified the frequency of null alleles, stutter bands and large allele dropout using the program MICROCHECKER 2.2.1 (van Oosterhout et al., 2004). Linkage disequilibrium was quantified using ARLEQUIN v3.1 (Excoffier et al., 2007). The overall $F$ statistics $\theta_{\mathrm{ST}}$ and $f$, measuring respectively the genetic structure and inbreeding rate, were quantified using FSTAT 2.93 (Goudet, 1995, 2001).

\section{RESULTS AND DISCUSSION}

The total number of alleles per locus ranged from 2-30 (median $=11.5$ alleles per locus; Table 2). There was no evidence of linkage disequilibrium between any pair of loci. Significant homozygote excess was found in six loci (Bi_115, Bi_116, Bi_117, Bi_121, Bi_128, and $\left.\mathrm{Bi}{ }_{-} 135\right)$ and were very likely in another locus (Bi_131; Table 2). MICROCHECKER found significant null alleles for three loci (Bi_116, Bi_117, and $\mathrm{Bi} 135$ ) but there was no evidence of stuttering or large allele dropout (Table 2). We therefore estimated the $F$-statistics across the five study populations using all loci complying with $\mathrm{HWe}(\mathrm{Bi} 111$, Bi_112, Bi_119, Bi_125, Bi_126, Bi_139, Bi_141, Bi_143, and Bi_144). The overall genetic structure was weak and marginally significant $\left(\theta_{\mathrm{ST}}=0.007,95 \% \mathrm{CI}=-0.001-0.017\right)$ and the inbreeding coefficient was significantly higher than zero $(f=0.067,95 \%$ $\mathrm{CI}=0.020-0.113)$. These nine highly polymorphic loci are hence hereby optimized for quick and cost effective genotyping. This dataset will be expanded to other surrounding $B$. ino populations (i) to determine the degree to which local populations are isolated and hence whether this system shows metapopulation structuring and dynamics; (ii) determine whether the observed genetic structure is due to barriers to gene flow and/or isolation by distance; and (iii) quantify the degree to which measures of local habitat quality influence the genetic characteristics of this butterfly species.

ACKNOWLEDGEMENTS. This work was financed by the Belgian Fonds de la Recherche Scientifique (F.R.S.-FNRS). C.L. and C.T. are F.R.S.-FNRS postdoctoral researchers, N.S. is F.R.S.FNRS Research Associate. This work is contribution BRC-331 of the Biodiversity Research Centre at UCL. We are grateful to two anonymous reviewers for their comments on a previous version of the manuscript, and H.D. Loxdale for his editorial suggestions.

\section{REFERENCES}

Excoffier L., Laval G. \& Schneider S. 2007: Arlequin (version 3.0): an integrated software package for population genetics data analysis. - Evol. Bioinform. Online 1: 47-50.

Fric Z., Hula V., Klimova M., Zimmermann K. \& Konvicka M. 2010: Dispersal of four fritillary butterflies within identical landscape. - Ecol. Res. 25: 543-552.

GoudET J. 1995: FSTAT Version 1.2: a computer program to calculate F-statistics. - J. Hered. 86: 485-486.

GoudET J. 2001: FSTAT, a program to estimate and test gene diversities and fixation indices (version 2.9.3). Available from http://www.unil.ch/izea/softwares/fstat.html. Updated from Goudet (1995).

Hall L.A. \& Beissinger S.R. 2014: A practical toolbox for design and analysis of landscape genetics studies. - Landsc. Ecol. 29: $1487-1504$.

HANSKi I. 1999: Metapopulation Ecology. Oxford University Press, Oxford, 328 pp.

Malausa T., Gilles A., Meglécz E., Blanquart H., Duthoy S., Costedoat C., Dubut V., Pech N., Castagnone-Sereno P., Delye C., Feau N., Frey P., Gauthier P., Guillemaud T., Hazard L., Le Corre V., Lung-Escarmant B., Malé J.P., Ferreira S. \& MARTIN J.F. 2011: High-throughput microsatellite isolation through 454 GS-FLX Titanium pyrosequencing of enriched DNA libraries. - Mol. Ecol. Res. 11: 638-644.

Meglécz E., Anderson A., Bourguet D., Butcher R., Caldas A., Cassel-Lundhagen A., Coeur D’Acier A., Dawson A.D., Faure N., Fauvelot C., Franck P., Harper G., Keyghobadi N., Kluetsche C., Muthulakshmi M., Nagaraju J., Patt A., Péténian F., Silvain J.F. \& Wilcock H.R. 2007: Microsatellite flanking region similarities among different loci within insect species. - Insect Mol. Biol. 16: 175-185.

Meglécz E., Costedoat C., Dubut V., Gilles A., Malausa T., Pech N. \& Martin J.-F. 2010: QDD: a user-friendly program to select microsatellite markers and design primers from large sequencing projects. - Bioinformatics 26: 403-404.

Molecular Ecology Resources Primer Development ConsorTIUM 2012: Permanent genetic resources added to molecular ecology resources database 1 April 2012 - 31 May 2012. Mol. Ecol. Resour. 12: 972-974.

NÈve G. \& MeglÉCZ E. 2000: Microsatellite frequencies in different taxa. - Trends Ecol. Evol. 15: 376-377.

Parmesan C., Ryrholm N., Stefanescu C., Hill J.K., Thomas C.D., Descimon H., Huntley B., Kaila L., Kullberg J., Tammaru T., Tennent W.J., Thomas J.A. \& Warren M. 1999: Poleward shifts in geographical ranges of butterfly species associated with regional warming. - Nature 399: 579-583.

RAYMOND M. \& RousSET F. 1995: GENEPOP (version 1.2): a population genetics software for exact tests and ecumenism. $-J$. Hered. 86: 248-249.

Sinama M., Dubut V., Costedoat C., Gilles A., Junker M., Malausa T., Martin J.F., Nève G., Pech N., Schmitt T., ZimmerMANN M. \& MegLécz E. 2011: Challenge for microsatellite development in Lepidoptera: Euphydryas aurinia (Nymphalidae) as a case study. - Eur. J. Entomol. 108: 261-266.

VANDEWOESTIJNE S. \& BAguetTe M. 2002: The genetic structure of endangered populations in the Cranberry Fritillary, Boloria aquilonaris (Lepidoptera, Nymphalidae): RAPDs vs allozymes. — Heredity 89: 439-445.

Van Oosterhout C., Hutchinson W.F., Willis D.P.M. \& Shipley P. 2004: Micro-checker: Software for identifying and correcting genotyping errors in microsatellite data. - Mol. Ecol. Notes 4: 535-538. 
Van Swaty C.A.M. \& Warren M. 1999: Red Data Book of European Butterflies (Rhopalocera). Nature and Environment 99, Council of Europe Publishing, Strasbourg, 264 pp.

Weyer J. \& SChmitT T. 2013: Knowing the way home: strong philopatry of a highly mobile insect species, Brenthis ino. - J. Insect Conserv. 17: 1197-1208.
Zimmermann K., Fric Z., Filipova L. \& Konvicka M. 2005: Adult demography, dispersal and behaviour of Brenthis ino (Lepidoptera: Nymphalidae): How to be a successful wetland butterfly. - Eur. J. Entomol. 102: 699-706.

Received November 20, 2014; revised and accepted December 28, 2014 Prepublished online February 27, 2015 